of Volume II are two little tables purporting to give the factors of what he calls "Trin-Aurifeuillian Quindecimans" and "Quint-Aurifeuillian Quindecimans", which, in plain English are factorizations of numbers of the forms $x^{15} \pm y^{15}$ after the algebraic divisors have been removed. Certain of the entries are left undecomposed, but at the head of the tables we are informed "All divisors less than 1,000 cast out". Nevertheless the following numbers on this page are left with a question mark:

$$
\begin{aligned}
& 17,780,401=151 \times 117,751 \\
& 17,354,461=181 \times 95,881 \\
& 15,679,621=211 \times 74,311 .
\end{aligned}
$$

The last number in the first table is $10,545,971$ which is an error for $10,545,991=151 \times 211 \times 331$. Also the number $25,437,261$ should be $125,437,261$. Moreover the complete examination of all the numbers left doubtful on this page ought not to occupy a skilful computer many hours. One questions the usefulness or importance of publishing a table of factors of "Trinomial Dimorph Sextans", of eight entries, containing only five complete factorizations, and leaving five factors undecomposed two of which, $12,419,509=2029 \times 6121$, and $13,401,901=1297 \times 10,333$, would have yielded without much effort.

In spite of the fact that the author had access (p. 171, vol. I.) to the recently published factor-tables he leaves doubtful, in Volume I such numbers as

$$
\begin{aligned}
& 9,705,193, \text { p. } 171 \text {, vol. I, } \\
& 9,670,849, \text { p. } 211 \text {, vol. I, } \\
& 9,843,601 \text {, p. } 217 \text {, vol. I, }
\end{aligned}
$$

and in Volume II we are given (p. 189) a question mark after 4, 144, 741.

These inaccuracies are, of course, not important in themselves, but show pretty clearly that these tables cannot be used in important work without careful checking.

\title{
D. N. LeHMER
}

Einführung in die Projective Geometrie Mehrdimensionaler Räume. By E. Bertini. Translated from the second Italian edition by A. Duschek. Wien, Seidel \& Sohn, 1924. 480 pp.

In 1860 Cremona, then thirty years of age, became Professor of Higher Geometry at the ancient University of Bologna. About thirty years later Italy led the world in research in geometry. Due chiefly to Cremona's influence, the field of projective geometry in hyperspace was developed with great vigor. Today this subject can be said to be almost wholly Italian. Much good work on the subject has been done outside of Italy but nowhere else has there been such an army of the ablest mathematicians working at it. Professor Bertini of the University of Pisa has contributed his share in this work and it is, 
therefore, fitting that the classical work on this subject should appear from his pen. Bertini has been lecturing for many years on $n$-dimensional projective geometry at Pisa and in 1899 a litographed edition of his lectures was published. This was revised and enlarged and finally appeared in print in 1907 . The second edition appeared in 1923. It is this second edition which Dr. Duschek has translated. It has now been so many years since the appearance of the first edition that it will be unnecessary to discuss the contents. I will, therefore, only mention the added material which this second edition contains. The aim has been to bring the work up to date and new theorems are added in many places. One new chapter has been inserted, Chapter XII, Moduli, representation of a form by linear combinations of others.

Let $F_{1}=0, F_{2}=0, \cdots, F_{h}=0$ be $h$ algebraic hypersurfaces (of order $\left.n_{1}, n_{2}, \cdots, n_{h}\right)$ in $n$-space, which intersect in a variety of $n-h$ dimensions.

$F_{1}, F_{2}, \ldots, F_{h}$ are called forms, and $\left(F_{1}, F_{2}, \cdots, F_{h}\right)$ is called the modulus. A form $F$ of order $r$ is said to belong to the modulus if

$$
F=A_{1} F_{1}+A_{2} F_{2}+\cdots+A_{h} F_{h}
$$

where the $A_{i}$ are forms of order $r-n_{i}$. This is expressed by writing

$$
F=0, \quad \bmod \left(F_{1}, F_{2}, \cdots, F_{h}\right) .
$$

The fact that the difference of two forms $F-F^{\prime}$ belongs to the modulus is expressed by

$$
F^{\prime}=F, \quad \bmod \left(F_{1}, F_{2}, \cdots, F_{h}\right) .
$$

A Schnitt of the modulus $\left(F_{1}, F_{2}, \cdots, F_{h}\right)$ is formed by connecting the coordinates by one or more linear relations.

With this introduction the problem is considered of finding the geometric conditions which the hypersurface $F=0$ must satisfy if $F$ can be written in the form

$$
F=0, \quad \bmod \left(F_{1}, F_{2}, \cdots, F_{h}\right) .
$$

To Chapter XIV (XIII of the first edition) has been added a discussion of the Segre variety which is defined as follows: Let

$$
\sum_{i=1}^{i=m} \lambda_{i} u_{k i}=0, \quad(k=1,2, \cdots, t),
$$

where the $\lambda$ 's are parameters and $u$ 's linear functions, be the equations of $t$ bundles of hyperplanes. The locus of points which will make the matrix of the $u$ 's of rank $m-h$ is the Segre variety and has many interesting properties.

The book has lost none of its attractiveness at the hands of the translator.

C. L. E. Moore 